\title{
A PATHWAY TO INITIATE BOTTOM-UP COMMUNITY-BASED DISASTER RISK REDUCTION WITHIN A TOP-DOWN SYSTEM: THE CASE OF CHINA
}

\author{
TIMOTHY SIM ${ }^{1}$, LENA DOMINELLI ${ }^{2} \&$ JOCELYN LAU $^{1}$ \\ ${ }^{1}$ Department of Applied Social Sciences, The Hong Kong Polytechnic University, \\ Hung Hom, Kowloon, Hong Kong. \\ ${ }^{2}$ School of Applied Social Sciences, Durham University, Durham, UK.
}

\begin{abstract}
In China, as in other countries, inadequate knowledge of local vulnerability and hazard characteristics, and a rapidly industrialising society render enhancing resilience to natural disasters particularly challenging. This is particularly evident in rural areas with limited human and financial resources available for disaster risk reduction initiatives. The Chinese government institutionalized a top-down community-based disaster risk reduction (CBDRR) system to ensure that the capacity of communities would be enhanced effectively. In the long run, a top-down management style often undermines local capacities and vernacular DRR (disaster risk reduction) knowledge. There is a need to recognize the importance of communities as complex and dynamic entities in reducing disaster risks. Adopting participatory action research (PAR), this in-progress exploratory study examines a pathway to initiate bottom-up CBDRR within China's top-down institutional setting. Through PAR, the study of a rural village in Shaanxi Province shows that bottom-up initiatives can complement the existing system. Its current progress demonstrates the potential for using a transdisciplinary perspective to initiate CBDRR in China, where both top-down and bottom-up approaches, come together alongside different disciplines to increase a rural community's disaster resilience.

Keywords: community, community-based disaster risk reduction (CBDRR), disaster risk reduction (DRR), Sendai Framework, rural China, top-down and bottom-up approaches to CBDRRR, participatory action research, natural disaster
\end{abstract}

\section{INTRODUCTION}

The Sendai Framework for Disaster Risk Reduction 2015-2030 acknowledges that 'disaster risk reduction' requires engagement and partnership with all-of-society because everyone is situated in a 'socio-cultural system' where rich people and poor, governments and societies alike, are affected when a disaster strikes. Responding to these events requires empowerment, inclusivity, accessibility, and non-discriminatory participation that pays special attention to the people disproportionately affected by disasters, especially the poorest ones [1]. The literature that explores the 'differentiated experiences of disaster' reveals that the basis for addressing the specific needs of groups whose vulnerabilities and capacities for resilience varies [2]. Moreover, disasters arise when a socio-cultural system fails to protect its population from external and internal vulnerability [3-6].

China is a signatory to the Sendai Framework. As the world's most populated and also a geographically stretched country, China is among the most vulnerable countries prone to natural disasters. Natural disasters in China are diverse, have high frequency, wide geographic distribution, significant damage and high disaster risks [7]. In parallel with advocacy on DRR by the United Nations Office for Disaster Risk Reduction (UNISDR), China has endorsed community-based disaster risk reduction (CBDRR) as a key component in its national strategies, e.g., the 11th, 12th and 13th Five Year Plans, for comprehensive disaster prevention and reduction. 
CBDRR represents a suite of methods embedded within communities to provide an operational process for supporting community resilience [8]. In the Western paradigm, DRR initiatives and knowledge are generated and 'owned' by communities [9] wherein local actors are at the heart of decision-making and implementation [10]. In contrast, CBDRR in China follows a top-down, government-led approach whereby local governments and communities are not involved in decision-making processes.

The Chinese government-led CBDRR strategy remains significant, and has produced some remarkable results. For instance, the low death toll during the magnitude 6.1 Ludian earthquake in Yunnan Province in 2014 has been attributed to this strategy. Nevertheless, this top-down disaster management is not without problems. It undermines local capacities and vernacular DRR knowledge; and underplays the heterogeneity of communities. In the long run, an alternative form of CBDRR initiatives is required in China to bridge the gap between the 'top' and the 'bottom' layers of society. In the face of marginal and limited discussions on bottom-up initiatives in China, this article considers what bottom-up CBDRR approaches are feasible within the predominantly top-down 'context' of China. What steps could be taken to mobilize communities and local actors to take a pro-active role in initiating CBDRR activities considering this national context?

This paper discusses an exploratory project in response to the above questions. Our research project has been running since 2012, but this article focuses on a pilot site located in a rural village in Shaanxi Province. We reflect upon iterative processes of discovery in the search for a complementary model that will effectively enhance the resilience of populations exposed to natural disasters by the end of the project in July 2017. We begin with a discussion of the concept of CBDRR, paying particular attention to its application in China. We then describe our journey of identifying a pathway to initiate CBDRR in this pilot site using participatory action research (PAR) methods.

\section{COMMUNITY-BASED DISASTER RISK REDUCTION (CBDRR)}

Community-based disaster risk reduction (CBDRR) is a process aimed at transforming passivity and powerlessness into action and resilience [11]. Despite a myriad of intrinsic elements and features, CBDRR consists of self-developed, culturally and socially acceptable, economically and politically feasible ways of coping with and avoiding crises related to natural hazards [11,12]. The Asian Disaster Preparedness Centre (ADPC), one of the earliest institutes to promote the practice of CBDRR through its training programmes, defines it as:

'a process in which at-risk communities are actively engaged in the identification, analysis, treatment, monitoring and evaluation of disaster risks in order to reduce their vulnerabilities and enhance their capacities. This means that people are at the heart of decision-making and implementation of disaster risk management activities. The involvement of [the] most vulnerable social groups is considered as paramount in this process, while the support of the least vulnerable groups is necessary for [its] successful implementation' [10].

At the core of this conceptualization, is the assumption that local communities are capable of responding to natural hazards on their own, as long as they are empowered and have adequate resources $[8,12,13]$.

To date, vulnerability is increasingly understood as socially-constructed $[4,6,8]$ and disasters are recognized as local events that first and foremost affect local communities [13]. It is logical to suggest that nobody is more interested in reducing risks of disasters than local people whose lives and livelihoods are threatened. Having more incentive to act, and the 
potential to mobilize and unlock the application of resources and know-how at the local level [12], local people can and should do more than simply react and respond to disasters. They should also be involved in preparing, planning and acting so that disaster risk is reduced [13].

Driven by international advocacy for a more people-centered approach to CBDRR, the Chinese government has drawn on the experience of other countries, and officially introduced the idea of community-based disaster risk reduction (shequ jianzai) in the National Plan, initially in the Comprehensive Disaster Reduction element of the Eleventh Five-Year Period in 2007. This emphasis on strengthening community capacity received institutional support through Chinese laws and regulations [14-18]. Specifically, the Chinese government perceived that the main methods for improving community capacity are by accurately assessing the levels of disaster risk at the community-level, improving the capacity of community engagement, and enhancing the capabilities of a community in disaster preparedness, reduction, response, and recovery [7].

The Chinese authorities introduced a series of national campaigns to implement CBDRR in China. For example, the Comprehensive Disaster Reduction Demonstration Community and Safe Community programmes were to be implemented by local governments to mainstream in their current practices the tasks of perfecting contingency plans, organizing emergency drills, and improving monitoring and early warning capacities [18]. These tasks entailed an explicit focus for enhancing community capacity on disaster prevention and reduction, and improving disaster management systems at community level [16]. All in all, the key objective for launching community-based disaster risk reduction in China by the authorities was to address effectively disaster risks and strengthen local capacities. These contemporary disaster risk reduction strategies also coincide with the goals of the Chinese developmental agenda.

However, unlike the trajectory of CBDRR implementation in other parts of the world, China applies it in a top-down fashion. The label of a top-down CBDRR system has thus emerged. Through it, the national government assumes key responsibilities in institutionalizing the concept of CBDRR and designing and applying the methodologies of community-based disaster risk assessment. The tasks of developing CBDRR by means of national campaigns such as the Demonstration Communities or Safe Communities are composed and assigned by central government to a community, level by level. Whereas the national and provincial governments introduce specific policies on CBDRR and assign tasks to their lower levels, local governments are responsible for undertaking the key tasks for developing CBDRR initiatives handed down by central government. Local governments are also responsible for all the expenditures incurred during the process of their implementation [18].

Others may argue that the outcome of such 'top-down' CBDRR remains uncertain as the effort of implementation is heavily dependent upon commitments and the financial capacities of each level of government within the overall administrative management system. Optimistically, initiating disaster risk activities in a top-down manner enables the concept to be put into action and sustained across the country quickly and efficiently. Tasks outlined through CBDRR campaigns could also materialize through standardization and become nationally applicable. In addition, by means of this management system, both local governments and communities would be given access to the necessary information and resources to actualize CBDRR. This, in turn, would empower not only communities, but also local governments involved in managing and reducing disaster risks in a given area [18].

In the long-run, the underlying weaknesses of a 'top-down' CBDRR strategy become apparent. Its tendency to assume that 'one size fits all' may fail to take into account local capacities and vernacular knowledge. For the same reason, this strategy is unable to 
recognize communities as complex and dynamic entities. Instead of being homogenous, communities are made up by diverse groups with different vulnerabilities, capacities and needs $[13,19]$. Vulnerability to disasters is differentiated according to age, disability, gender, ethnicity and other social divisions, including class expressed through poverty [20, 21]. People's exposure to vulnerabilities and experiences to disasters in China are particularly varied, as a result of the rapid pace of urbanization, and the expansion of the income gap across regions. These socio-economic conundrums indicated that the 'one-size-fits-all strategy' is not a sustainable solution for addressing disaster risks in China.

Besides, it is increasingly recognized that simple one-way transfers of 'expert' information are inadequate. In this globalized world, effective communication is at the core of all activities in which experts are be involved, including in reducing disaster risks [22]. To cope better with the increasingly uncertain, complex and ambiguous risks and hazards, exchanges of knowledge, experiences and concerns among actors of various backgrounds and at different levels become important and constitutive of meaningful and effective communication [2224]. Being more attentive to local capacities and vernacular knowledge regarding CBDRR is in line with the contemporary need for a substantial reduction of disaster risk and that requires 'perseverance and persistence' [1].

While the Chinese top-down CBDRR system is effective in putting the concept of CBDRR into practice, in the long-run, it is necessary to spell out more explicitly the role of multiple stakeholders in framing and implementing disaster risk reduction and resilience building endeavours to plug the gaps left by a 'top-down' approach to CBDRR. Given its strong 'topdown' capacity to coordinate and distribute resources quickly within disaster-stricken areas, China has a great potential in facilitating the successful integration of the 'top-down' and 'bottom-up' approaches. This could involve a sharing of 'responsibilities among central governments and relevant authorities, sectors and stakeholders, as appropriate to the national circumstances and systems of governance' [1].

In light of the limited discussion on the process and effect of initiating bottom-up CBDRR endeavours within a top-down context, this exploratory study aims to shed light on the feasibility of implementing bottom-up CBDRR efforts in China, where the government is actively involved in advancing the DRR agenda. Specifically, we employ participatory action research (PAR) strategies, with the aim of bridging the gaps between scientific knowledge and vernacular knowledge; between theoretical and practical CBDRR; and between top-down interventions and bottom-up initiatives [25].

\section{PARTICIPATORY ACTION RESEARCH (PAR)}

As we explore a bottom-up approach to CBDRR in China, we shall delineate our aims for 'bottom-up' CBDRR in our project. In the short-run, a bottom-up approach to CBDRR would actively engage local people in the identification, analysis, treatment, monitoring and evaluation of disaster risks to reduce their vulnerabilities and enhance their resilience capacities. This means that people, particularly vulnerable social groups, are at the heart of decision-making and implementation of disaster risk management activities [23]. In the long-run, the DRR knowledge and capacities of local communities, households, authorities and other local stakeholders would engage in DRR incorporated by and legitimized within the Chinese disaster management framework. That is, we anticipate a CBDRR model with Chinese characteristic that has both the community and government integrated within one holistic framework.

Participatory action research (PAR) was adopted as the guiding framework for this exploratory study to examine the pathway of getting the local actors, namely, the local village head, 
secretary, and residents to take a pro-active role in initiating CBDRR. PAR methods have a long history in the social sciences and have been used extensively for DRR planning and implementation around the world. It significantly enhances the disaster resilience of local stakeholders via the co-production of 'hybrid' knowledge that combines local and outside specialist knowledge [25]. On the other hand, instead of theoretical discussions, PAR encourages communities, researchers and local authorities to work together in all stages of disaster risk reduction $[25,26]$ to find solutions to their problems and develop action plans owned by the community [21].

With PAR, research is no longer seen as solely a means of creating and disseminating knowledge. Instead, it is also a process of education, a development of consciousness and a call to action for DRR [26-31]. Although the participants in this study are residents from a rural village with relatively low literacy rates, we regard them as expert community-based 'knowers' and valorize their knowledges and experiences. The researchers and village participants enter into a reciprocal relationship in a research process wherein external researchers do not presume to have a superior perspective. This creates a safe environment that fosters bottom-up initiatives. Therefore, in the pilot site, the rural villagers are full partners in the research processes and they, like us, are referred as co-researchers [26, 29, 31].

\section{PATHWAY TO INITIATING BOTTOM-UP CBDRR}

\subsection{Working together: Integrate DRR and local community development programme}

The interdisciplinary research team, consisted of four overseas researchers (two social workers, one seismologist, one social policy scholar and one research assistant), who worked closely with an established local non-governmental organization (NGO) in China. This NGO has focused on community development and promoted earthquake disaster resilience in Shaanxi province since 2013. The province experienced the Huaxian Earthquake in 1556 that killed more than 830,000 people. We identified C County with the help of the local seismological bureau to consider known geophysical hazards in Shaanxi. C County has been constantly affected by hailstorms and drought, but has not faced earthquakes in recent decades. The research team aimed to increase the earthquake resilience of $\mathrm{C}$ County by integrating DRR with a community livelihood development project run in C Village in Shaanxi Province under the auspices of the local NGO. The livelihood project focused on promoting tourism in the village given its strategic location near several famous historical sites and plantations of apples which would enable villagers to attract tourists from towns and cities. The NGO has been working closely with C Village since 2014 and has successfully engaged the local village committee, local leaders and residents in these activities.

\subsection{Baseline study: Gaining an understanding of the local context}

DRR planning and implementation require salient community-based information. It seeks to identify potential coping capacities and resources, the availability of support networks, and local knowledge of their vulnerabilities and the hazards to which they are exposed [25]. The next step we took was to conduct a baseline study of C Village.

Prior to the baseline study, desk research of local and international tools was conducted to identify a CBDRR baseline tool which was appropriate for the rural Chinese context. This enabled us to identify a gap, namely that there are few accessible CBDRR baseline tools in 
the Chinese literature. We then embarked on developing a toolkit relevant for investigating local disaster risk reduction capacities and villagers' perceptions of different types of natural disasters. Once the toolkit was designed, feedback from social scientists, natural scientists, local NGOs and our co-researchers both in China and overseas were sought and the tool was revised accordingly. Ethical approval was provided by the Hong Kong Polytechnic University via the Human Subjects Ethics Application Review System. The date of approval was 3 May 2015 and the reference number is HSEARS20150503001.

The baseline study was conducted between 4 and 14 March 2016. Five trained field staff went door to door to visit every household in C Village to interview all available villagers aged 13 or above. In the end, 230 villagers took part in the baseline study where 219 questionnaires were valid for analysis. In brief, we found that:

- Participants were most concerned about hailstorms, followed by drought, then earthquake hazards;

- Participants with primary school education or below have a significantly weaker preparedness for natural disasters than those with education level of junior high and above; and

- Children have the strongest preparedness for disasters, followed by heads of household (usually men), the spouses of heads of households and parents of the heads of households.

These findings above suggested that older people and women were the groups more vulnerable to disasters in C Village. Overall, the baseline study enabled us to: (a) engage with our coresearchers; (b) understand the ways in which different elements within the community have adapted to the risk contexts; and (c) the way CBDRR knowledge is understood by different co-research groups. This step provided a preliminary understanding of the complex interplay of resilience and vulnerability to disasters in the village, and how these are embedded in other aspects of everyday living. These form important knowledge for co-researchers to educate each other, and inform the next steps in the co-production processes that lead to action.

\subsection{In-depth interview: Interacting with 'representatives' of co-researchers}

The analysis of the baseline study produced a surprise for the authors. We learned that although our pilot site is not far from the epicenter of the 1556 Shaanxi earthquake, the study revealed that our co-researchers were not only unfamiliar with that earthquake, but they also had limited experiences with earthquakes in general, despite the recent 2008 Wenchuan earthquake which did have a severe impact on some counties nearby [32].

In view of the knowledge gap identified by the baseline study, we sought to understand further what life narratives, histories, cultural contexts, socio-economic conditions and governance structures existed in the village, and what impact they may have had on the issues of resilience, vulnerability, and risk.

Therefore, an indicative in-depth interview was conducted with a specific focus on two identified vulnerable groups: middle-aged women (aged between 40 and 60) and older people (aged 60 or above). In a nutshell, these interviews highlighted that:

- Hailstorms were the natural disaster most often experienced in C Village;

- Recovery was conducted independently on a household basis after previous hailstorms (versus a neighbourhood/community approach whereby members mutually helped one another); 
- Village norms and insufficient resources were the main reasons for the lack of support between neighbours;

- Availability of funding was instrumental in determining a family's preparedness for hailstorms;

- Villagers were not ignorant about the impact of earthquake-related hazards;

- Villagers have an exclusive focus on engineering, especially housing, for earthquake preparedness; and

- Villagers are keen to learn about CBDRR.

In addition, three specific types of needs for enabling our co-researchers to carry out CBDRR in the village were identified: financial support from the government, CBDRR education and the availability of hail cannons (to fire into the sky and prevent hailstones from dropping on their crops).

\subsection{An interactive field study: knowledge acquisition through action learning}

Based on the findings above, the authors were delighted to find out that the villagers were keen to learn about CBDRR. To our knowledge, although bottom-up CBDRR initiatives are rare in China, there are NGOs that have been working closely with local governments on CBDRR. After consulting with the villager committee members and some of the villagers, a field study was organized for them to learn about the CBDRR experience of Y County in Shaanxi province. This field study served as an action learning process to expose co-researchers and other key local stakeholders to CBDRR practices; and for them to make direct observations and learn lessons about the process and possible products of CBDRR in a rural setting within their own province.

In this field study, 12 co-researchers were exposed to DRR drill demonstrations that were targeted at various hazard types, ranging from household fires to landslides, in two rural villages in Y County. Both formal and informal interactions between the co-researchers and NGOs representatives, government officials, were facilitated during the visit. Informal interactions occurred over meals and breaks. During the formal discussion session, the co-researchers of Y County, including local government officials were invited to share their views and experiences of developing CBDRR initiatives. Co-researchers from C Village were also engaged in the debriefing session later when they reflected on the CBDRR knowledge that they had gained through this visit, and were enabled to explore potential facilitators and obstacles in implementing CBDRR activities appropriate to their own village. The impact of this interactive field study was apparent immediately, especially considering their insight and motivation. The co-researchers pointed out:

- the importance and necessity of governmental support and involvement in their CBDRR activities;

- the need to build a comprehensive local CBDRR system, which involves the building of a CBDRR committee, and a coordination and communication mechanism.

\subsection{Consultation: Action prioritization}

After the field trip, the research team collaboratively ranked the key CBDRR activities appropriate for $\mathrm{C}$ Village with the co-researchers and NGO staff who have been working in $\mathrm{C}$ 
Village. The objective was to facilitate and guide local stakeholders in producing a detailed plan outlining the content and processes for CBDRR implementation.

Owing to the low literacy rate of some of the co-researchers, pictures were utilized to help explain the types of activities that were identified based on the findings and discussions from the previous steps in engaging them. Specifically, co-researchers were asked to rank independently the CBDRR activities to be carried out according to their needs and those of their family members.

For the next step of this ongoing project, the authors and local NGO staff will be helping the co-researchers to set up their own CBDRR system with reference to the national frameworks, followed up by designing with them the CBDRR activities that they deem relevant. CBDRR experts from local universities and relevant government departments within China's DRR system will also be invited to join the consultations around designing and carrying out these activities where relevant.

\section{DISCUSSION}

Maskrey [12] highlighted the essence of CBDRR is "neither specifically, nor particularly about implementing mitigation measures exclusively at the community level of action, but the progressive activation of all the levels, starting with the community itself'. We believe there is value in going beyond 'persuading the community to participate in government-based mitigation programs, and to persuade government at all levels to participate in communities' own programmes'[12]. This will form the basis of the integration of a top-down with a bottom-up approach.

On the other hand, although the origin of the CBDRR concept emerged in the 1970s as an alternative paradigm to challenge the predominantly top-down strategy of disaster management then practiced worldwide [11, 13], our exploration for a bottom-up CBDRR initiative in China does not advocate such a polarized vision. On the contrary, we seek to explore a complementary approach to plug the gaps left by top-down approaches that ignore community needs and capacities. Bottom-up CBDRR initiatives in China can utilise the heterogeneity of a community and integrate the disparate elements of local CBDRR knowledge into the existing top-down CBDRR system.

Although this is only an exploratory study, we are able to layout a pathway that introduces a bottom-up CBDRR approach in the Chinese context through the use of a PAR framework. Whether the approach is top-down or bottom-up, the ultimate goal should be to enhance effectively the resilience of communities to disasters. Future studies on CBDRR can, therefore, learn from this iterative process whereby villagers are invited as co-researchers to work with a range of stakeholders from different disciplines and sectors (governmental and non-governmental) and locations (other counties and overseas) to co-design the research agenda throughout the process of increasing the disaster resilience of village co-researchers in a community development project.

\section{CONCLUSION}

It is recognized that CBDRR initiatives often consist of self-developed, culturally and socially acceptable, economically and politically feasible ways of coping with and avoiding crises related to natural hazards $[11,12]$. By adopting the participatory action research framework, this study provided multiple opportunities to empower practitioners and co-researchers to construct vernacular knowledge and integrate CBDRR practices in ways that are unique and practical to the context of China. 
This ongoing study attempts to identify a pathway to initiate bottom-up CBDRR endeavours in a rural village setting in China. The authors began by pulling the available resources to work together to integrate CBDRR into the local community development programme. Next, we sought to understand the local context and local knowledge about hazard characteristics, vulnerability of people and their ability to prepare and cope with disasters. We then acquired more in-depth information about the vulnerable groups' coping mechanisms and adaptation, post-disaster mitigation and preparedness, lived experiences of disasters and specific CBDRR needs. Nine months after the baseline study, the co-researchers and local stakeholders were involved in an interactive field visit to other rural villages in Shaanxi, where there were some established CBDRR products and activities initiated by non-governmental bodies. Based on their observation and lessons learned, the co-researchers became more confident and capable of mapping out the CBDRR activities that are appropriate for their own village.

Overall, different skills and mixed methods were used for different steps involved throughout the exploratory activities. To learn about existing CBDRR capacity and the needs of the community, we employed PAR methods such as surveys, participant observation, and in-depth interviews. One of the characteristics of PAR is that data collection and analysis cannot be separated. Hence, we carefully documented each step we took. Moreover, we analyzed the data collected in an iterative fashion and constantly reflected upon the previous results. More importantly, information sharing and discussions with co-researchers on a constant basis in advance of planning out details and actions formed an integral part of our methodology. Our overall conclusion at this stage is that this exploratory study reflects that participatory action research is a feasible approach for identifying a pathway for initiating bottom-up CBDRR initiatives in the context of China because its processes serve as a foundation whereby to complement the current top-down disaster management system.

\section{ACKNOWLEDGEMENTS}

This study is an integral part and funded by the Earthquakes without Frontiers project (Grant number: NE/J01995X/1). We would like to extend our thanks to the local collaborators: Shaanxi Seismological Bureau, Shaanxi Gender Development Solution, World Vision International - China Office, and local government officials for their support. We would also like to thank the co-researchers, i.e., the village committee members and residents of $\mathrm{C}$ Village who kindly agreed to engage fully in this study.

\section{REFERENCES}

[1] United Nations Office for Disaster Risk Reduction (UNISDR). The Sendai Framework for Disaster Risk Reduction 2015-2030, 2015.

[2] Dominelli, L., Environmental Justice at the heart of social work practice: greening the profession. International Journal of Social Welfare, 22(4), pp. 431-439, 2013. https://doi.org/10.1111/ijsw.12024

[3] Barton, A.H., Social Organization Under Stress, National Research Council, National Academy of Sciences: Washington, DC, 1963.

[4] Dynes, R.R., Coming to terms with community disaster. In What is a Disaster: Perspectives on the Question, ed. E.L. Quarantelli, Routledge: London, pp. 109-126, 1998.

[5] Bates, F.L. \& Peacockm, W.G., Living Conditions, Disasters and Development, University of Georgia Press: Athens, 1993. 
[6] Oliver-Smith, A., Global challenges and the definitions of disaster. In What is a Disaster: Perspectives on the Question, ed. E.L. Quarantelli, Routledge: New York, pp. 177-194, 1998.

[7] Shi, P.J., Wang, M. \& Ye, Q., Achievements, experiences and lessons, challenges and opportunities for china's 25-year comprehensive disaster reduction. In: Planet @ Risk, 2(5), Special Issue for the Post-2015 Framework for DRR: pp. 353-358, Global Risk Forum GRF Davos, Davos, 2014.

[8] Wisner, B. \& Kelman, I., Community Resilience to Disasters. In International Encyclopedia of the Social and Behavioral Sciences, 2nd edn., ed. E.L. Quarantelli, Elsevier: Oxford, vol. 4, pp. 354-360. 2015.

https://doi.org/10.1016/B978-0-08-097086-8.28019-7

[9] Amaratunga, C.A., Building community disaster resilience through a virtual community of practice (VCOP). International Journal of Disaster Resilience in the Built Environment, 5(1), pp. 66-78. 2014. https://doi.org/10.1108/IJDRBE-05-2012-0012

[10] Abarquez, I. \& Zubair, M., Community-Based Disaster Risk Management: Field Practitioners' Handbook, ADPC (Adapted from CBDRM-II course materials), 2004.

[11] Luna, Emmanuel, M., Community-based disaster risk reduction and disaster management. In Disaster Management: International Lessons in Risk Reduction, Response and Recovery, eds A. López-Carresi, B. Wisner, I. Kelman \& J.C. Gaillard, Routledge: New York, pp. 43-63, 2013.

[12] Maskrey, A., Revisiting community-based disaster risk management. Environmental Hazards, 10(1), pp. 42-52, 2011. https://doi.org/10.3763/ehaz.2011.0005

[13] Delica-Willison, Z. \& Gaillard, J.C., Community action and disaster. In B. Wisner, I. Kelman \& J.C. Gaillard, Handbook of Hazards and Disaster Risk Reduction, Routledge: New York. pp. 711-722, 2012.

[14] Jiang, L.I., Implementation of disaster reduction measures and enhancement of integrated risk governance in China. International Journal of Disaster Risk Science, 4(2), pp. 101-104, 2013. https://doi.org/10.1007/s13753-013-0011-0

[15] Zhai, G.F., Li, S.S. \& Chen, J., Reducing urban disaster risk by improving resilience in China from a planning perspective. Human and Ecological Risk Assessment: An International Journal, 21(5), pp. 1206-1217, 2015. https://doi.org/10.1080/10807039.2014.955385

[16] Zhang, X., Yi, L.X. \& Zhao, D., Community-based disaster management: a review of progress in China. Journal of the International Society for the Prevention and Mitigation of Natural Hazards, 65(3), pp. 2215-2239, 2013. https://doi.org/10.1007/s11069-012-0471-3

[17] Zou, M. \& Yi, Y., China's comprehensive disaster reduction. International Journal of Disaster Risk Science, 1(1), pp. 24-32, 2010.

[18] Feng, X.J. \& Wang, D.M., Policy Analysis of Community-Based Disaster Risk Reduction in China, Peking University Press: Beijing, 2014.

[19] Anderson, M.B. \& Woodrow, P.J., Rising From the Ashes: Development Strategies in Times of Disaster, Lynne Rienner: London, 1989.

[20] Dominelli, L., Sim, T. \& Ke, C., Community-based approaches to disaster risk reduction in China. In Report: Pathways to Earthquake Resilience in China, Overseas Development Institute, October 27, 2015. 
[21] Dominelli, L., Green Social Work, Cambridge: Polity Press, 2012.

[22] Renn, O., Klinke, A. \& van Asselt, M., Coping with complexities, uncertainty and ambiguity in risk governance: a synthesis. Ambio, 40, pp. 231-246, 2011. https://doi.org/10.1007/s13280-010-0134-0

[23] Rodriguez, H., Diatz, W., Santos, J.M. \& Aguirre, B.E., Communicating risk and uncertainty: science, technology, and disasters at the crossroads. In Handbook of Disaster Research, eds H. Rodriguez, E.L. Quarantelli, R.R. Dynes, Springer: New York, pp. 476-488, 2007. https://doi.org/10.1007/978-0-387-32353-4_29

[24] Benn, S., Dunphy, D. \& Martin, A., Governance of environmental risk: new approaches to managing stakeholder involvement. Journal of Environmental Management, 90, pp. 1567-1575, 2009. https://doi.org/10.1016/j.jenvman.2008.05.01

[25] McCall, M.K. \& Peters-Guarin, G., Participatory action research and disaster risk. In Handbook of Hazards and Disaster Risk Reduction, eds B. Wisner, I. Kelman, J.C. Gaillard, Routledge: New York, pp. 772-786, 2012.

[26] McIntyre, A., Participatory Action Research, Sage Publications, 2007.

[27] Park, P., People, knowledge, and change in participatory research. Management Learning, 30(2), pp. 141-157, 1999. https://doi.org/10.1177/1350507699302003

[28] Reason, P. \& Hilary, B., The SAGE Handbook for Action Research: Participative Inquiry and Practice, SAGE: London, 2008. https://doi.org/10.4135/9781848607934

[29] Small, S.A., Action-oriented research: models and methods. Journal of Marriage and Family, 57(4), pp. 941-955, 1995. https://doi.org/10.2307/353414

[30] Kindon, S., Pain, R. \& Kesby, M., (eds). Participatory Action Research Approaches and Methods: Connecting People, Participation and Place, Routledge: London, 2007.

[31] Schruijer, S.G.L., Research on collaboration in action. International Journal of Action Research, 2(2), pp. 222-224, 2006.

[32] Wang, F., Cheng, Q.G. \& Highland, L., Preliminary investigation of some of the large landslides triggered by the 2008 Wenchuan earthquake, Sichuan Province, China. Landslides, 6, pp. 47-54, 2009. https://doi.org/10.1007/s10346-009-0141-z 